\title{
Down-Regulation of Akt Expression Plays an Important Role in Embryonic Arrest
}

\author{
Guan $Y^{1}$, Guo H', Qu Q ${ }^{2}$, Xia $Y^{2}$, Zhong $X^{2}$ and Shi \\ $\mathbf{L}^{1 *}$ \\ ${ }^{1}$ Department of Obstetrics and Gynecology, Hebei \\ Medical University Fourth Affiliated Hospital and Hebei \\ Provincial Tumor Hospital, Shijiazhuang, China \\ ${ }^{2}$ Guangzhou Exon Biotechnology Inc, Guangzhou, China \\ *Correspondling author: Li Shi, Department of \\ Obstetrics and Gynecology, the Fourth Hospital of Hebei \\ Medical University, Shijiazhuang, 050011, China
}

Received: August 09, 2021; Accepted: September 08, 2021; Published: September 15, 2021

\begin{abstract}
Embryonic arrest patients are increasing in worldwide, but its reason remains unknown. Our objective is to detect the Akt expression in the decidual tissues and chorionic tissues of embryonic arrest patients and to explore if it play important role in embryonic arrest. The decidual tissues and chorionic tissues of 18 pregnant women with a second embryonic arrest and 20 pregnant women with a first embryonic arrest were collected, and 18 pregnant health women were used as controls group. Next immunohistochemistry was adopted to detect the expression of Akt expression in decidual tissues and chorionic tissues. Compared to control group, the expression of Akt protein in the decidual tissues and chorionic tissues of the one-time group and two-time group both were significantly reduced $(p<0.05)$. In addition, we summarize and analyze the gene knockout mice phenotype of PI3K/Akt pathway, these literatures support our results. And Akt1, Akt2, and Akt3 exist a mutual compensation effect. Interestingly, Akt1 knockout directly affects the development of the fetus. In conclusion, the PI3K/Akt signaling pathway is involved in the process of embryonic development and is closely related to embryonic arrest.
\end{abstract}

Keywords: Akt; Embryonic arrest; PI3K-Akt pathway; Immunohistochemistry

\section{Introduction}

Embryonic arrest is a pathological pregnancy in which early embryos stop developing and some embryos remain in the mother's body due to their own defects in the fertilized egg or the mother's abnormal conditions that are not conducive to pregnancy [1]. But embryonic development errors reason still keep mysteries at the beginning of mammalian life [2]. At present, the main causes of embryo arrest reported including: chromosomal abnormalities, placental abnormalities, environmental factors and endocrine abnormalities [3,4].

Akt is a serine/threonine protein kinase, also known as protein kinase $\mathrm{B}(\mathrm{PKB})$, acts as a major signal transducer downstream of activated phosphoinositide 3-kinase and is related with development [5]. Studies have used transcriptome sequencing and Small RNA-seq, and introduced mRNA and miRNA integration analysis to identify key genes and miRNAs. It was found that most of the differentially expressed genes are enriched in the PI3K-Akt signaling pathway. Related genes can regulate cell migration, angiogenesis, and apoptosis, thereby affecting early embryonic development [6], and those studies have shown that through the treatment of recurrent abortion mice upregulate the Akt signaling pathway, which can promote maternal and fetal angiogenesis and improve embryo survival $[7,8]$, showing that Akt is closely related to embryonic arrest.

In this study, we detected the expression of Akt on the decidual tissues and chorionic tissues of normal abortion and embryonic arrest, respectively, in order to understand the occurrence and correlation of Akt's effect on embryonic arrest. The expression of Akt in the decidual tissues and chorionic tissues of the one-time group and twotime group was significantly lower compared to normal group. It is helpful for exploring the mechanism of PI3K/Akt signaling pathway in the process of embryonic arrest.

\section{Materials and Methods}

\section{Study subjects}

Thirty-eight pregnant women with unexplained vaginal bleeding, who had been referred to the Department of Obstetrics and Gynecology of the Fourth Hospital of Hebei Medical University, Shijiazhuang, China, between January 2017 and December 2018, After confirmed embryonic development stopped by B-ultrasound combined with human chorionic gonadotropin ( $\beta$-hCG), were enrolled in the test group.

Of them, 20 pregnant women with the first embryonic arrest were as the one-time group, and 18 pregnant women with the second embryonic arrest were as the two-time group. In addition, 18 pregnant women with normal embryonic development who had undergone B-ultrasound examination and required artificial abortion during the same period were selected as the normal group. All study subjects have not taken hormone drugs recently, have no bad habits, and have no history of other genetic diseases. All subjects were informed that tissue samples would be used for research propose only. And the study was approved by the Ethic Committee of the Fourth Hospital of Hebei Medical University (NO. 2016MEC122).

\section{Sample pretreatment}

The corresponding decidual tissues and chorionic tissues are collected, washed, dehydrated, fixed, and finally embedded in conventional paraffin, and then cut into frozen section with a thickness of 5-8 $\mu \mathrm{m}$.

\section{Immunohistochemistry}

Tissue dewaxing and hydration: place the precut decidual tissues 
and chorionic tissues on a slide and heat the slide at $65^{\circ} \mathrm{C}$ for 20 minutes, deparaffinize with xylene substitute, and then hydrate it with ethanol solution with multiple concentration gradients, wash with distilled water. Antigen retrieval was treated with citrate buffer microwave, and then washes twice with PBS buffer. Antibody incubation: block with $3 \% \mathrm{BSA}$ at $37^{\circ} \mathrm{C}$ for 30 minutes, then drop the Anti-Akt antibody (bsm-33325M, Bioss Co., Ltd, Beijing, China) to incubate overnight at $4^{\circ} \mathrm{C}$, wash twice with PBS solution. Then add the Goat Anti-Mouse IgM/HRP antibody as a secondary antibody, incubate at $37^{\circ} \mathrm{C}$ for 1 hour, and wash twice with PBS buffer. Use DAB kit (Solarbio, Beijing, China) for color development. Observe the results with a microscope (Nikon 80i, Japan).

The positive result of Akt protein presents brown in the cytoplasm or nucleus. The percentage of positive cells observed and the color depth are comprehensively scored under microscope, that is, the overall percentage $\leqq 10 \%$ is (-), score 0 point; $11 \%-25 \%$ is $(+)$, score 1 point; $26 \%-50 \%$ is $(++)$, score 2 points; $>50 \%$ is $(+++)$, score 3 points. The results were scored by two persons that have relevant experience and one is pathologist, and some scores with different opinions were reviewed for the second time to finally update scores.

\section{Statistical analysis}

All statistical analyses were performed using GraphPad Prism 8 software. Data were expressed as means \pm standard deviation (SD). The results between groups were analyzed by t-test and one-way ANOVA. A value of $\mathrm{P}<0.05$ was considered statistically significant.

\section{Results}

\section{Correlation analysis of embryonic arrest and clinical data}

The comparison of the three groups of clinical data showed that the average age of the normal group was $(27.9 \pm 6.4)$ years, the one-time group was $(30.8 \pm 6.0)$ years, and the two-time group was $(31.4 \pm 5.0)$ years. There was no significant difference in age, Body Mass Index (BMI), hemoglobin number and leukocyte number among the three groups (Table 1, P >0.05).The pregnancy time of the one-time group and the two-time group was slightly higher than that of the normal group (Table $1, \mathrm{P}<0.05$ ), which may be related to the early artificial abortion of the normal group. And the number of dysmenorrhea in the two-time group was significantly higher than that of the normal group and the one-time group (Table $1, \mathrm{P}<0.05$ ). The results showed that embryonic arrest was mainly concentrated in the ninth and tenth weeks, and was related to clinical indicators of dysmenorrhea, but not related to age, BMI, hemoglobin number, and leukocyte number.

\section{Akt expression is decreased in decidual tissue of embryo stop}

For us, to clear whether Akt, as a functional molecule of the PI3K signaling pathway, play a role in embryo arrest. Immunohistochemistry was used to detect Akt in the decidual tissue of one-time embryo arrest, two-time embryo arrest, and normal abortion. The results showed that Akt was mainly expressed in the nucleus of the decidual tissue. Akt was strongly positively expressed in the decidual tissue of the normal group, and weakly positive or negatively expressed in the decidual tissue of the one-time group and two-time group shown in Figure 1.

The statistical analysis of Akt in the three groups of decidual tissues showed that Akt was significantly different between the three groups $(\mathrm{F}=4.628, \mathrm{P}<0.05)$. Compared with the normal group, the Akt expression in the decidual tissue of the one-time group $(\mathrm{t}=2.066)$ and the two-time group $(t=2.456)$ was significantly reduced, and the difference was statistically significant $(\mathrm{P}<0.05$, Table 2$)$.

\section{Akt expression is also reduced in chorionic tissue of embryo stop}

The above results suggest that the expression of Akt in the decidual tissue, and decidual tissue is an important medium for the mother to feed the embryo, Akt is decreased significantly in chorionic tissue of embryo stop. But, what is the expression of Akt in the chorionic tissue which is an important medium for the embryo to actively absorb nutrients? For this reason, we detected the Akt in the chorionic tissue of three groups. The results showed that Akt was mainly expressed in the nucleus of chorionic tissue. Akt was strongly positively expressed in the chorionic tissue of the normal group, and weakly positive or

Table 1: Comparison results of general clinical data.

\begin{tabular}{|c|c|c|c|c|c|c|c|}
\hline Group & $\mathbf{n}$ & Age (yrs) & Pregnancy time (d) & BMI (kg/m $\mathbf{m}^{2}$ & Hemoglobin (g/L) & Leukocyte (10 $/$ L) & Dysme norrhea (case) \\
\hline Normal & 18 & $27.9 \pm 6.4$ & $49.5 \pm 9.1$ & $21.3 \pm 3.1$ & $127.5 \pm 12.0$ & $8.0 \pm 2.3$ \\
\hline One-Time & 20 & $30.8 \pm 6.0$ & $68.1 \pm 13.9^{*}$ & $23.5 \pm 3.9$ & $128.5 \pm 10.2$ & $8.3 \pm 2.2$ \\
\hline Two-Time & 18 & $31.4 \pm 5.0$ & $64.3 \pm 9.3^{*}$ & $23.5 \pm 3.4$ & $130.6 \pm 10.3$ & $8.3 \pm 2.8$ \\
\hline
\end{tabular}

*Significantly different from normal group $(p<0.05)$.

"Significantly different from one-time group $(p<0.05)$.

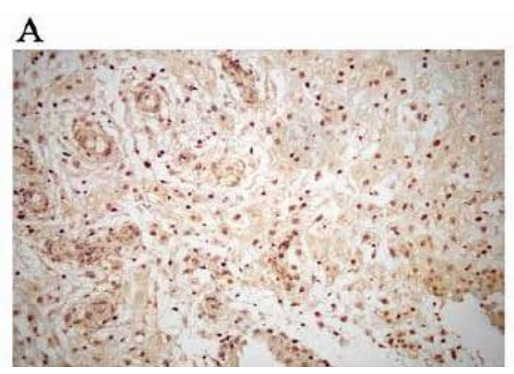

\section{B}

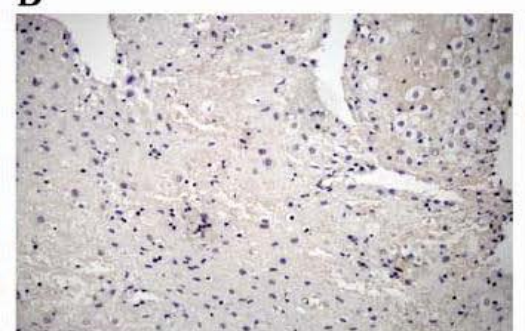

C

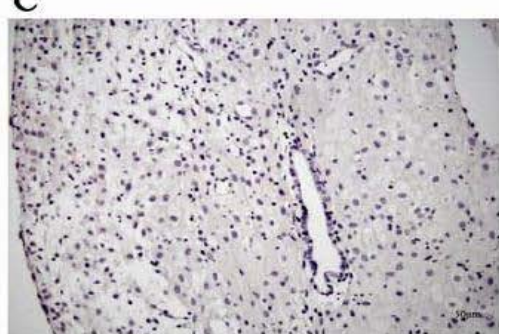

Figure 1: Immunohistochemical results of Akt in decidual tissue. A) The representative image of Decidual tissue being staining with Akt antibody in normal group. B) Decidual tissue in the one-time group. C) Decidual tissue in the two-time group. The positive signal appears brown indicating Akt expression. Magnification: $\times 200$. 
Table 2: The scores of Akt expression in decidual tissue.

\begin{tabular}{|c|c|c|c|c|c|c|c|c|}
\hline \multirow{2}{*}{ Group } & \multirow{2}{*}{$\mathbf{n}$} & \multicolumn{4}{|c|}{ Expression of Akt protein } & \multirow{2}{*}{ Positive rate (\%) } & \multirow{2}{*}{$\mathbf{F}$} & \multirow{2}{*}{$\mathbf{P}$} \\
\hline & & - & + & ++ & +++ & & & \\
\hline Normal & 18 & 11 & 4 & 0 & 3 & $38.88 \%$ & \multirow{4}{*}{4.628} & \multirow{4}{*}{0.014} \\
\hline One-Time & 20 & 18 & 1 & 1 & 0 & $10.00 \% *$ & & \\
\hline Two-Time & 18 & 17 & 1 & 0 & 0 & $5.55 \%{ }^{*}$ & & \\
\hline Total & 56 & 46 & 6 & 1 & 3 & $17.53 \%$ & & \\
\hline
\end{tabular}

*Significantly different from normal group $(p<0.05)$.

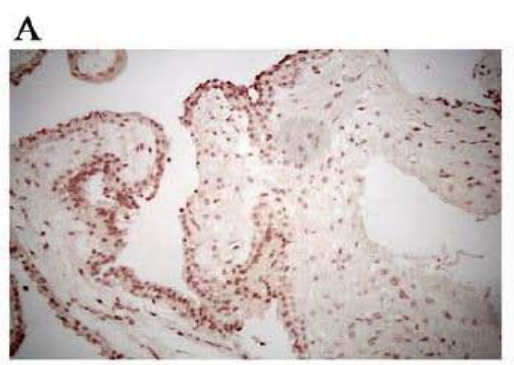

$\mathbf{B}$

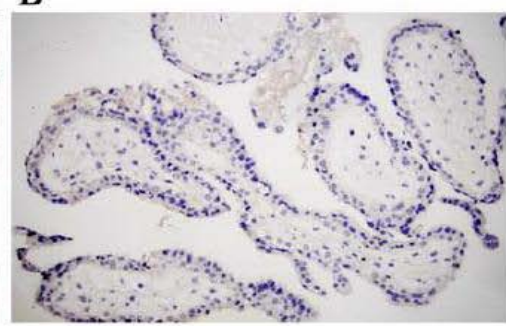

C

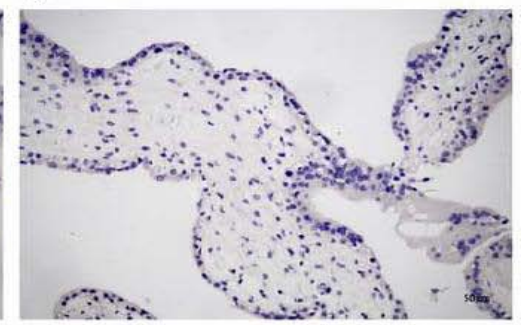

Figure 2: Immunohistochemical results of Akt in chorionic tissue. A) The representative image of chorionic tissue being staining with Akt antibody in normal group. B) Chorionic tissue in the one-time group. C) Chorionic tissue in the two-time group. The brown is positive signal. Magnification: $\times 200$.

Table 3: Expression results of Akt in chorionic tissue.

\begin{tabular}{|c|c|c|c|c|c|c|}
\hline \multirow{2}{*}{ Group } & \multirow{2}{*}{$\mathbf{n}$} & \multicolumn{3}{|c|}{ Expression of Akt protein } & \multirow{2}{*}{ Positive rate (\%) } \\
\cline { 3 - 6 } & & - & + & ++ & +++ & $55.55 \%$ \\
\hline Normal & 18 & 8 & 3 & 3 & 4 & $40.00 \%$ \\
\hline One-Time & 20 & 12 & 5 & 2 & 1 & $27.77 \%$ ** \\
\hline Two-Time & 18 & 13 & 5 & 0 & 0 & 4.309 \\
\hline Total & 56 & 33 & 13 & 5 & 5 & 0.018 \\
\hline
\end{tabular}

*Significantly different from normal group $(p<0.01)$

negatively expressed in the chorionic tissue of the one-time group and two-time group (Figure 2).

Compared with the normal group, the expression of the onetime group decreased to a certain extent, but the difference was not significant $(\mathrm{P}>0.05)$; while the expression of Akt protein in the chorionic tissue of the two-time group $(\mathrm{t}=2.834)$ was significantly reduced, and the difference was statistically significant $(\mathrm{P}<0.01$, Table 3).

\section{Most Akt related gene knockout mice present abnormal embryonic development}

To explore or understand whether the Akt signaling pathway plays an important role in embryonic arrest, we collected the reported studies, finding that $40 \%$ of Akt1 knockout mice had obvious development defects in the Akt subtype knockout transgenic mice. Akt2 gene and Akt3 gene knockout mice have no obvious fertility abnormalities. Akt1 ${ }^{-/} \mathrm{Akt}^{+/-}$mice die early after full-term birth, while $\mathrm{Akt}^{+/-}$and $\mathrm{Akt}^{-/-}$mice survived normally, indicating that Akt1 gene is more important for mouse embryonic reproduction and development than Akt3; And $\mathrm{Aktt}^{-/} \mathrm{Akt}^{-/}$double knockout mice die early after birth, compared with $\mathrm{Akt1}^{-/-} \mathrm{Akt}^{+/-}$mice, which also die early after full-term birth, it shows that Akt3 is more important than Akt2 in embryonic reproduction and development. Therefore, it is concluded that Akt1 effect is high that Akt3 effect, Akt3 effect is high than Akt2 effect in mouse reproduction and development [9]. At the same time, the upstream molecules of Akt signaling pathway, PIK3CA gene and PIK3CB gene knockout mice also have birth defects, while PIK3CG gene knockout mice and PIK3CD gene knockout mice have no obvious reproductive defects. It shows that the catalytic subunits expressed by PIK3CA and PIK3CB are directly related to Akt1 protein, we summary those studies in Table 4 .

\section{Discussion}

According to reports, among women planning to become pregnant, the incidence of early embryonic arrest is $10 \%-25 \%$. China's 1997 National Population and Reproductive Health Survey, show that the rate of embryonic arrest in the country was about $5 \%$, but it was as high as $8 \%$ in some areas, and it was gradually increasing, although some regional reports data are still no updated reports of national embryonic arrest [2].

Embryonic arrest mainly occurs within 12 weeks of pregnancy, and the main reasons are related to chromosomal abnormalities, placental abnormalities, environmental factors and endocrine abnormalities. The clinical data of our study showed that embryonic arrest was generally concentrated in the ninth and tenth weeks, and had a certain correlation with the occurrence of dysmenorrhea. Embryonic arrest had nothing to do with age, BMI, hemoglobin number, and leukocyte number. Embryonic arrest often causes a serious psychological burden on women and their families. At the same time, the etiology of embryonic arrest is very complicated, and the specific mechanism is not yet clear. The placenta is particularly 
Table 4: knockout mice of PI3K/Akt phenotype.

\begin{tabular}{|c|c|c|c|}
\hline Gene & Findings & Fertility & Reference \\
\hline Akt1 & $\begin{array}{l}\text { The apoptotic rate of mice testis cells increased, } \\
\text { spermatozoa decreased. }\end{array}$ & $\begin{array}{l}\text { Most of the mice died in the middle of embryo or early birth, } \\
\text { and a small number of surviving mice were delayed }\end{array}$ & {$[10,11]$} \\
\hline $\mathrm{Akt1}^{-1-} \mathrm{Akt}^{+/-}$ & $\begin{array}{l}\text { The angiogenesis of the mice placenta is weakened, and various } \\
\text { defects appear in the thymus, heart and skin. }\end{array}$ & Mice die early after full-term birth & [13] \\
\hline $\mathrm{Akt1}^{-1} \mathrm{Akt3}^{-\digamma}$ & Mice placental blood vessel development is defective & $\begin{array}{l}\text { Mice embryo is severely delayed and die around embryonic } \\
\text { day } 11 \text { and } 12\end{array}$ & [13] \\
\hline $\mathrm{Akt1}^{+/-} \mathrm{Akt}^{-/-}$ & Defects in brain development & No obvious defects & [13] \\
\hline Akt2 & diabetes & No obvious defects & {$[14,16]$} \\
\hline Akt3 & Weight loss of the brain & No obvious defects & {$[15,16]$} \\
\hline $\mathrm{PIK} 3 \mathrm{ca}^{--}$ & $\begin{array}{l}\text { Embryonic fibroblasts lack signals, cannot differentiate into adipocytes, } \\
\text { and have defects in angiogenesis. }\end{array}$ & $\begin{array}{l}\text { Mice embryo is delayed around day } 9 \text { and die } \\
\text { around embryonic day } 10\end{array}$ & {$[17,18]$} \\
\hline PIK3cb-1- & Early embryonic death & Early embryonic death & [19] \\
\hline PIK3 $\mathrm{cg}^{-/-}$ & Renal tubular cell apoptosis & No obvious defects & [20] \\
\hline $\mathrm{PIK} 3 \mathrm{~cd}^{-1-}$ & Decreased number of B cells & No obvious defects & [21] \\
\hline
\end{tabular}

critical as an important medium between the embryo and the mother. The development of its decidual tissue and chorionic tissue is closely related to pregnancy.

Recently many researcher have discovered that a variety of genes or proteins act on embryonic development around the PI3K/Akt signaling pathway [10]. The decrease in Akt expression may lead to decreased expression of other genes or weakened metabolism, which in turn affects the embryonic development and causes abortion. Here, the immunohistochemical was used to detect the expression of Akt in the decidual and chorionic tissues of multiple groups of subjects. The results showed that Akt was mainly expressed in the nucleus of decidual and chorionic tissue. The expression of Akt in decidual tissue and chorionic tissue of patients with embryonic arrest was significantly lower than that of the normal group. It shows that the decrease of Akt expression is related to the occurrence of embryonic arrest. It may be that the decrease of Akt causes abnormal expression of decidua and chorion function, or decreased angiogenesis, so insufficient blood supply to the placenta, dysmenorrhea, etc. Akt insufficient occur affects embryo support and leads to embryonic arrest.

Akt is a protein kinase that regulates a variety of enzymes and transcription factors, thereby regulating cell functions. Among them, the PKBa/Aktl subtype mainly acts on the development of the placenta and blood vessels. The Akt1 gene knockout mice have slow growth, weight loss, and have About $40 \%$ of mice die [11,12], Akt1 has an indispensable influence on reproduction and development. The PKB $\beta /$ Akt2 subtype mainly acts on the pancreas. Akt2 knockout mice show severe type 2 diabetes [13], and Akt2 is extremely important in glucose metabolism. The $\mathrm{PKB} \gamma / \mathrm{Akt} 3$ subtype mainly acts on the brain [9]. The volume and weight of the brain of Akt3 gene knockout mice are reduced [14]. Akt3 has a certain necessary connection to the development of the brain. Although these three subtypes are expressed in different parts, the compensation effect of Akt3 on Akt1 is greater than that of Akt2 in fertility, and there is a fertility effect Akt1>Akt3>Akt2 [9]. The PIK3CA and PIK3CB genes are important genes encoding the catalytic subunits of PI3K. Their gene knockout mice also have fertility defects, which knockout causes Ser/Thr kinase Akt and other downstream growth factors to fail to activate, blocking normal Signal pathway, and thus unable to regulate the proliferation, survival and migration of a variety of cells [15-17]. In addition, PIK3CG knockout mice and PIK3CD knockout mice have no obvious reproductive defects $[18,19]$. The catalytic subunits expressed by PIK3CA and PIK3CB are directly related to Aktl subtypes.

In summary, the expression level of Akt in the decidual tissue and chorionic tissue of patients with embryonic arrest was significantly lower than that of the normal group. PI3K/Akt signaling pathway is also involved in the process of embryonic development and is closely related to the occurrence of embryonic arrest. Detecting Akt expression level has certain significance for the early evaluation of the occurrence of embryonic arrest, and provides an early indicator for clinical pregnancy. But its specific mechanism of action still needs to be further studied.

\section{Declaration}

Authors' contributions: Study design and Conception: Li Shi and Qiqi Qu; Data collection, analysis, and interpretation: Yingxia Guan, Hui Guo, Qiqi Qu; Samples collection and treated: Yingxia Guan, Yuanmei Xia, Xinchao Zhong; Statistical analysis: Yingxia Guan, Qiqi $\mathrm{Qu}$; Manuscript writing and critical revisions of manuscript: Li Shi, Yingxia Guan

Acknowledgments: We thank Professor Jiangchao Li (Guangdong Pharmaceutical University, Guangzhou, China) for his support and help in pathological analysis. We also thank all doctors (Department of Obstetrics and Gynecology, the Fourth Hospital of Hebei Medical University, Shijiazhuang, China) for their assistance in specimen collection.

Grant support: This work was supported by grants from Key Medical Research Project of Health Department of Hebei Province, China (Grant ID: 20160175).

\section{References}

1. Del Gobbo GF, C Konwar and WP Robinson. The significance of the placental genome and methylome in fetal and maternal health. Hum Genet. 2020; 139: 1183-1196.

2. Schneider I and J Ellenberg. Mysteries in embryonic development: How can errors arise so frequently at the beginning of mammalian life? PLoS Biol. 2019; 17: e3000173. 
3. Romero ST, et al. Differentiation of genetic abnormalities in early pregnancy loss. Ultrasound Obstet Gynecol. 2015; 45: 89-94.

4. D'Antonio F, et al. Embryonic growth discordance and early fetal loss: the STORK multiple pregnancy cohort and systematic review. Hum Reprod. 2013; 28: 2621-2627.

5. Dummler B and BA Hemmings. Physiological roles of PKB/Akt isoforms in development and disease. Biochem Soc Trans. 2007; 35: 231-235.

6. Yang ZZ, et al. Dosage-dependent effects of Akt1/protein kinase Balpha (PKBalpha) and Akt3/PKBgamma on thymus, skin, and cardiovascular and nervous system development in mice. Mol Cell Biol. 2005; 25: 10407-10418.

7. Luan $X$, et al. Down-regulation of CCR7 via AKT pathway and GATA2 inactivation suppressed trophoblast migration and invasion in recurren spontaneous abortiondagger. Biol Reprod. 2020; 102: 424-433.

8. Zheng J, et al. Involvement of CXCL12/CXCR4 in the motility of human firsttrimester endometrial epithelial cells through an autocrine mechanism by activating PI3K/AKT signaling. BMC Pregnancy Childbirth. 2020; 20: 87.

9. Tschopp O, et al. Essential role of protein kinase B gamma (PKB gamma/ Akt3) in postnatal brain development but not in glucose homeostasis. Development. 2005; 132: 2943-2954.

10. Peng XD, et al. Dwarfism, impaired skin development, skeletal muscle atrophy, delayed bone development, and impeded adipogenesis in mice lacking Akt1 and Akt2. Genes Dev. 2003; 17: 1352-1365.

11. Chen WS, et al. Growth retardation and increased apoptosis in mice with homozygous disruption of the Akt1 gene. Genes Dev. 2001; 15: 2203-2208.
12. Cho $\mathrm{H}$, et al. Akt1/PKBalpha is required for normal growth but dispensable for maintenance of glucose homeostasis in mice. J Biol Chem. 2001; 276: 38349-38352.

13. Garofalo RS, et al. Severe diabetes, age-dependent loss of adipose tissue, and mild growth deficiency in mice lacking Akt2/PKB beta. J Clin Invest. 2003; 112: 197-208.

14. Yang ZZ, et al. Physiological functions of protein kinase B/Akt. Biochem Soc Trans. 2004; 32: 350-354

15. $\mathrm{Bi} \mathrm{L}$, et al. Proliferative defect and embryonic lethality in mice homozygous for a deletion in the p110alpha subunit of phosphoinositide 3-kinase. J Biol Chem. 1999; 274: 10963-10968.

16. Zhao JJ, et al. The p110alpha isoform of PI3K is essential for proper growth factor signaling and oncogenic transformation. Proc Natl Acad Sci USA. 2006; 103: 16296-16300

17. Bi L, et al. Early embryonic lethality in mice deficient in the $\mathrm{p} 110$ beta catalytic subunit of PI 3-kinase. Mamm Genome. 2002; 13: 169-172.

18. Kuwana $\mathrm{H}$, et al. The phosphoinositide-3 kinase gamma-Akt pathway mediates renal tubular injury in cisplatin nephrotoxicity. Kidney Int. 2008; 73 : 430-445.

19. Clayton $\mathrm{E}$, et al. A crucial role for the p110delta subunit of phosphatidylinositol 3-kinase in B cell development and activation. J Exp Med. 2002; 196: 753763 